докт. сель.-хоз. наук, проф. Кузык А.Д. / prof. Kuzyk A.D., Ph.D. ${ }^{1}$

Товарянский В.И. / Tovaryanskiy V.I. ${ }^{1}$

Przyjęty/Accepted/Принята: 25.05.2014;

Zrecenzowany/Reviewed/Рецензирована: 01.09.2015;

Opublikowany/Published/Опубликована: 30.09.2015;

\title{
Оценка влажности хвои сосны обыкновенной как фактора пожарной опасности по измерению ее диэлектрической проницаемости ${ }^{2}$
}

\author{
Fire Hazards Caused by Dielectric Permittivity - Evaluation of Pine \\ Needles Moisture Content
}

\author{
Ocena wilgotności igieł sosny zwyczajnej jako czynnika zagrożenia pożarowego, \\ poprzez pomiar przenikalności elektrycznej
}

\begin{abstract}
АННОТАЦИЯ
Цель: Оценить влажность хвои сосны обыкновенной как одного из важных пожароопасных показателей по ее электрофизическим свойствам с последующей возможностью экспресс-диагностики опасности пожара в сосновых лесах . Проанализировать влияние физико-химических свойств хвои на уровень пожарной опасности.

Введение: Влажность хвои сосны обыкновенной обусловливает ее пожарную опасность.

Поскольку традиционные методы определения влажности требуют много времени или соответствующих заранее откалиброванных инструментов и методов их использования, предложено оценивать влажность хвои сосни обыкновенной по ее диэлектрической проницаемости, отображенной в ёмкости конденсатора, между пластинами которого размещена хвоя.

Проект и методы: Экспериментальные исследования сушки хвои проводились в лаборатории. Сосновые иглы содержались в помещении при температуре $20 \pm 1^{\circ} \mathrm{C}$ и относительной влажности воздуха $46 \pm 2 \%$ до достижения равновесной влажности. Затем хвою поместили в сушильный шкаф на 2 часа при температуре $100 \pm 5^{\circ} \mathrm{C}$ до достижения абсолютно сухого состояния. Влажность рассчитывали для каждого дня исследований весовым методом, используя лабораторные весы. Диэлектрическую проницаемость хвои оценивали ёмкостью плоского конденсатора, между пластинами которого помещали фиксированное количество хвойных игл. Конденсатор подключали к измерителю емкости. Для обработки результатов применяли методы статистического анализа с использованием соответствующего программного обеспечения.

Результаты: Изменения диэлектрической проницаемости отображены в изменении ёмкости конденсатора, между пластинами которого размещена хвоя. Получены зависимости влажности хвои от времени сушки и ёмкости конденсатора с хвоей между пластинами от времени сушки. Ёмкость конденсатора предполагали пропорциональной диэлектрической проницаемости, из чего следует, что диэлектрическая постоянная уменьшается одновременно с влажностью. Используя элементы регрессионного анализа, найдены линейные и полиномиальные эмпирические модели, описывающие зависимости влажности хвои сосны обыкновенной от емкости конденсатора. Определение непосредственно диэлектрической проницаемости хвои затруднено из-за того, что между пластинами конденсатора находится не только хвоя, но и воздух. В связи с этим для проведения экспресс-диагностики пожарной безопасности хвои сосны обыкновенной вместо диэлектрической проницаемости рекомендуем использовать значение ёмкости конденсатора с хвоей внутри.

Выводы: Влажность хвои сосны обыкновенной отображается в ёмкости конденсатора с хвоей между пластинами, что дает возможность оценивать степень пожарной опасности.
\end{abstract}

Ключевые слова: пожарная опасность, хвоя, влажность, ёмкость конденсатора, сосна обыкновенная, диэлектрическая проницаемость среды

Вид статьи: оригинальная научная работа

\footnotetext{
Львовский государственный университет безопасности жизнедеятельности / Lviv State University of Life Safety, Ukraine; andrii_k@yahoo.com;

2 Авторы внесли одинаковый вклад в создание статьи / The authors contributed equally to this article;
} 


\section{A BSTRACT}

Aim: To carry out an evaluation of pine needles moisture content, an important factor which contributes to fire hazards as a result of dielectric properties. Such an evaluation facilitates a speedy diagnosis of a fire hazard in pine forests An analysis was performed on the impact of physical and chemical properties of pine needles on the potential fire hazard

Introduction: Moisture content of pine needles has an impact on properties associated with fire hazards. Traditional moisture determining methods consume much time and require specialist pre-calibrated measuring instruments and techniques. Therefore, the article proposes a method of evaluating pine needles moisture content, based on dielectric permittivity principles, expressed by the capacitance of a capacitor containing pine needles located between its plates.

Project and methods: Experimental studies of dry pine needles were performed in a laboratory. Pine needles were stored at the constant air temperature of $20 \pm 1^{\circ} \mathrm{C}$ and relative humidity of $46 \pm 2 \%$ until uniform moisture content was achieved. Subsequently, the pine needles were dried for 2 hours, in an oven, at a temperature of $100 \pm 5^{\circ} \mathrm{C}$. The moisture content of pine needles was determined for each day of research by weighing, using laboratory scales. The dielectric permittivity of pine needles was evaluated with the aid of a flat capacitor, by placing a specified number of pine needles between its plates. This capacitor was connected to a capacitance measuring device. Statistical analysis methods and corresponding software were used for data processing.

Results: Dielectric permittivity changes were mapped using changes to the capacitor's capacitance, with pine needles located between its plates. Identified the dependence relationships between moisture content of pine needles and drying time, as well as capacitance of the capacitor containing pine needles and drying time. Capacitance is proportional to dielectric permittivity, therefore, dielectric permittivity falls in parallel with a decrease in moisture content. Using regression analysis, linear and polynomial trends were identified, describing the dependence relationship between moisture content of needles and capacitance. Direct quantification of dielectric permittivity of pine needles is complicated by the presence of air among pine needles located between plates. Therefore diagnosis of a fire hazard should be performed using capacitance of a capacitor with pine needles between its plates rather than dielectric permittivity.

Conclusions: Evaluation of pine needles moisture content, with pines located between the plates of a capacitor, has an impact on the capacitor's capacity, which facilitates a speedy prediction of fire hazard levels.

Keywords: fire hazard, pine needles, moisture, capacitor capacitance, scots pine, dielectric permittivity Type of article: original scientific article

\section{A B S T R A K T}

Cel: Przeprowadzenie oceny wilgotności igieł sosny zwyczajnej, jednego z ważnych czynników zagrożenia pożarowego, na podstawie ich właściwości elektro-fizycznych, która umożliwi szybką diagnostykę zagrożenia pożarowego w lasach sosnowych; przeanalizowanie wpływu fizycznych i chemicznych właściwości igieł na stopień zagrożenia pożarowego.

Wprowadzenie: Wilgotność igieł sosny zwyczajnej wpływa na ich właściwości pożarowe. Ponieważ tradycyjne metody określania stopnia wilgotności wymagają znacznego nakładu czasu lub odpowiednich i precyzyjnych narzędzi oraz sposobów ich użycia, w artykule zaproponowana została metoda oceny wilgotności igieł sosny zwyczajnej na podstawie przenikalności elektrycznej, wyrażonej w pojemności kondensatora z igłami sosny umieszczonymi między jego okładkami.

Projekt i metody: Badania eksperymentalne wysuszonych igieł były prowadzone w laboratorium. Igły sosny były przechowywane w pomieszczeniu o temperaturze $20 \pm 1^{\circ} \mathrm{C}$ i względnej wilgotności powietrza $46 \pm 2 \%$ aż do uzyskania zrównoważonej wilgotności. Następnie igły umieszczono na 2 godziny w suszarce w temperaturze $100 \pm 5^{\circ} \mathrm{C}$ do osiągnięcia stanu całkowicie suchego. Każdego dnia badań wartość wilgotności wyliczano poprzez ważenie igieł z wykorzystaniem wag laboratoryjnych. Przenikalność elektryczną oceniano na podstawie pojemności płaskiego kondensatora, pomiędzy okładki którego umieszczono określoną ilość igieł. Kondensator był podłączany do miernika pojemności. W celu przetwarzania wyników wykorzystano metody analizy statystycznej i odpowiednie oprogramowanie. Wyniki: Wraz ze zmianą przenikalności elektrycznej następowały zmiany pojemności kondensatora, w którym znajdowały się igły rozłożone między okładkami. Otrzymano zależność między wilgotnością igieł a czasem suszenia oraz pojemnością kondensatora z igłami między okładkami a czasem suszenia. Pojemność kondensatora odpowiadała proporcjonalne przenikalności elektrycznej, wskazując, że stała dielektryczna zmniejsza się jednocześnie z wilgotnością. Wykorzystując elementy analizy regresyjnej, otrzymano liniowe i wielomianowe modele empiryczne opisujące zależności między wilgotnością igieł sosny a pojemnością kondensatora. Określenie bezpośrednio przenikalności elektrycznej igieł jest utrudnione, ponieważ pomiędzy okładkami poza igłami znajduje się również powietrze. W związku z tym do przeprowadzenia szybkiej diagnostyki bezpieczeństwa pożarowego zamiast przenikalności elektrycznej autorzy rekomendują wykorzystanie wartości pojemnościowej kondensatora z igłami.

Wnioski: Wilgotność igieł sosny zwyczajnej ma wpływ na pojemność kondensatora, w którym są one rozłożone. Ta zależność umożliwia ocenę stopnia zagrożenia pożarowego.

Słowa kluczowe: zagrożenie pożarowe, igły, wilgotność, pojemność kondensatora, sosna zwyczajna, przenikalność elektryczna otoczenia Typ artykułu: oryginalny artykuł naukowy

\section{1. Введение}

В связи с большим спросом на древесину в народном хозяйстве интенсифицируется вырубка деревьев, что приводит к освобождению участков леса. С целью обеспечения рационального природопользования участки засаживают молодыми деревьями, в том числе и хвойными. Хвойные молодняки - лесная среда, в которой в случае возникновения пожара процессы горения протекают особенно интенсивно, а такие параметры пожара, как периметр, площадь и скорость распространения фронта пламени быстро растут, что затрудняет тушение и влечет за собой уничтожение леса на значительных площадях. Поэтому актуальной задачей является предотвращение возникновения пожаров молодого хвойного леса. Мероприятия по предупреждению пожара требуют меньших затрат 
времени и средств по сравнению с его тушением. При этом возникает необходимость использования существующих и разработки новых методов экспресс-диагностики пожарной опасности хвойных насаждений.

Хвойный молодой лес имеет самый высокий показатель пожарной опасности по шкале природной пожарной опасности И. С. Мелехова [1]. Наиболее распространенной хвойной породой в лесах Украины является сосна обыкновенная (pinus sylvestris L). Сосновые леса сосредоточены в Полесье, на востоке и юге страны [2]. Эти леса, особенно при отсутствии в составе их древостоев лиственных пород, составляют высокую пожарную опасность. Заметим, что сосна в молодом возрасте в составе насаждений с ее участием отличается от деревьев старшего возраста низким расположением ветвей, что в случае низового пожара способствует его переходу в верховой. Наибольшую пожарную опасность составляет сосновая хвоя, которая в живом состояние удерживается на ветвях деревьев 2-3 года, а в случае сосновых молодняков - и до 4 лет. Хвоя сосны молодого возраста более пожароопасна по сравнению с хвоей сосны старшего возраста [3]. Повышенная пожарная опасность хвои обусловлена увеличенным содержанием органических веществ, которым свойственны высокие пожароопасные показатели, - скипидара и терпентинового масла, а также зависит от содержания воды, которая также обуславливает ее диэлектрические свойства [4]. Содержание воды не является постоянным и со временем изменяется. Этому процессу способствуют различные факторы, обуславливающие влажность почвы, в частности эдафические и погодно-климатические условия. Кроме этого, влажность хвои зависит и от особенностей лесных насаждений: структуры древостоя, возраста, сомкнутости крон и т.п.

\section{2. Цель исследования}

Исследовать возможность оценки влажности хвои сосны обыкновенной как фактора пожарной опасности по ее диэлектрической проницаемости, отображенной в ёмкости конденсатора. Ёмкость - это свойство накапливания электрического заряда материалом. Диэлектрическая проницаемость характеризирует изоляционные свойства материала. Значения этих параметров являются важными показателями физиологических свойств хвои сосны, которые влияют на пожароопасные свойства и обуславливают возникновение пожара.

При распространении пожара происходит сушка и пиролиз горючего материала, расположенного вблизи пламени. Существующие шкалы измерения пожарной опасности лесов классифицируют ее по значению влажности лесного материала [7]. Влажность горючих материалов определяют весовым методом, что требует много времени и наличия специальных устройств - сушильных шкафов, или с помощью влагомеров, которые являются дорогостоящими, требуют предварительной калибровки, а также специфических методов измерения. Поэтому актуальной задачей является разработка и практическое использование доступных методов экспресс-диагностики влажности хвои сосны обыкновенной, исходя из физических свойств этого пожароопасного материала.

\section{3. Инструменты и методы}

В ходе проведения исследований использованы измеритель ёмкости UT-601, лабораторные весы и электрическая сушильная камера 2В151. Влажность хвои определяли весовым методом по формуле [5]:

$$
=\frac{G_{1} \quad G_{2}}{2} \cdot 100 \%
$$

где $G_{1}$ - исходная масса образца до сушки, г, а $G_{2}$ - маса после сушки до абсолютно сухого состояния, г.

Диэлектрическую проницаемость оценивали по значению ёмкости плоского конденсатора, состоящего из двух текстолитовых пластин размером 30-40 мм, покрытых медной фольгой. Расстояние между пластинами 5 мм. Аналогичный метод применялся в [6] для оценки влажности листьев деревьев по ёмкости.

\section{4. Результаты}

Исследования проводились в течение 26 дней в два этапа. В течение первого этапа получили зависимости влажности хвои и ёмкости конденсатора с хвоей между его пластинами от времени сушки в лабораторных условиях. Начало проведения эксперимента - 16 февраля, окончание - 13 марта 2014 г. Для исследования в лесу вблизи города Львов отобрана хвоя сосны обыкновенной возрастом 7 лет. Из хвои сформировали пять образцов по 30 иголок (хвоинок) в каждом. Образцы размещались в помещении с температурой воздуха $20 \pm 1^{\circ} \mathrm{C}$ и относительной влажностью $46 \pm 2 \%$ на листах бумаги. Ежедневно в одно и то же время образцы взвешивали и измеряли емкость конденсатора с внесенными между пластинами образцами хвои. Результаты измерений приведены в табл. 1.

Таблица 1. Массы образцов хвои и ёмкости конденсатора с хвоей в процессе сушки

Table 1. Mass of pine needles samples and capacitance of the capacitor with needles samples inside during drying

\begin{tabular}{|c|c|c|c|c|c|c|c|}
\hline \multirow{3}{*}{$\begin{array}{c}\text { День } \\
\text { эксперимента / } \\
\text { Day of the } \\
\text { experiment }\end{array}$} & \multirow{3}{*}{ Дата / Date } & \multicolumn{6}{|c|}{ Масса образцов, г/ Ёмкость, пФ / Mass of samples, g/Capacitance, pF } \\
\hline & & \multicolumn{5}{|c|}{ Образцы / Samples } & \multirow{2}{*}{$\begin{array}{c}\text { Среднее } \\
\text { значение / } \\
\text { Average value }\end{array}$} \\
\hline & & 1 & 2 & 3 & 4 & 5 & \\
\hline 1 & 16.02 .14 & $2,64 / 37,70$ & $2,52 / 37,80$ & $2,55 / 36,60$ & $2,37 / 34,90$ & $2,32 / 38,60$ & $2,48 / 37,20$ \\
\hline 2 & 17.02 .14 & $2,37 / 27,60$ & $2,26 / 31,10$ & $2,29 / 28,80$ & $2,12 / 29,20$ & $2,04 / 29,70$ & $2,22 / 29,28$ \\
\hline 3 & 18.02 .14 & $2,15 / 27,30$ & $2,07 / 32,20$ & $2,09 / 27,20$ & $1,93 / 28,10$ & $1,86 / 28,30$ & $2,02 / 28,62$ \\
\hline
\end{tabular}




\begin{tabular}{|c|c|c|c|c|c|c|c|}
\hline \multirow{3}{*}{$\begin{array}{c}\text { День } \\
\text { эксперимента / } \\
\text { Day of the } \\
\text { experiment }\end{array}$} & \multirow{3}{*}{ Дата / Date } & \multicolumn{6}{|c|}{ Масса образцов, г/ Ёмкость, пФ / Mass of samples, g/Capacitance, pF } \\
\hline & & \multicolumn{5}{|c|}{ Образцы / Samples } & \multirow{2}{*}{$\begin{array}{c}\text { Среднее } \\
\text { значение / } \\
\text { Average value }\end{array}$} \\
\hline & & 1 & 2 & 3 & 4 & 5 & \\
\hline 4 & 19.02 .14 & $2,02 / 27,60$ & $1,92 / 30,30$ & $1,94 / 24,60$ & $1,79 / 26,20$ & $1,75 / 27,30$ & $1,89 / 27,20$ \\
\hline 5 & 20.02 .14 & $1,86 / 28,60$ & $1,80 / 26,30$ & $1,81 / 30,30$ & $1,67 / 25,60$ & $1,65 / 25,70$ & $1,76 / 27,26$ \\
\hline 6 & 21.02 .14 & $1,75 / 25,70$ & $1,69 / 24,60$ & $1,71 / 26,10$ & $1,57 / 23,40$ & $1,56 / 25,70$ & $1,66 / 25,10$ \\
\hline 7 & 22.02 .14 & $1,67 / 25,70$ & $1,59 / 24,00$ & $1,6 / 24,40$ & $1,46 / 23,20$ & $1,45 / 23,50$ & $1,55 / 24,16$ \\
\hline 8 & 23.02 .14 & $1,59 / 23,7$ & $1,51 / 24,00$ & $1,53 / 23,90$ & $1,39 / 22,70$ & $1,43 / 23,60$ & $1,49 / 23,58$ \\
\hline 9 & 24.02 .14 & $1,52 / 23,10$ & $1,44 / 24,00$ & $1,45 / 24,90$ & $1,33 / 22,60$ & $1,34 / 24,00$ & $1,42 / 23,72$ \\
\hline 10 & 25.02 .14 & $1,44 / 23,60$ & $1,36 / 23,30$ & $1,36 / 21,60$ & $1,26 / 21,30$ & $1,23 / 24,20$ & $1,33 / 22,80$ \\
\hline 11 & 26.02 .14 & $1,34 / 20,80$ & $1,24 / 22,10$ & $1,25 / 21,60$ & $1,14 / 20,30$ & $1,13 / 21,10$ & $1,22 / 21,18$ \\
\hline 12 & 27.02 .14 & $1,32 / 20,80$ & $1,24 / 21,20$ & $1,24 / 20,00$ & $1,17 / 19,20$ & $1,13 / 19,10$ & $1,22 / 20,60$ \\
\hline 13 & 28.02 .14 & $1,30 / 20,60$ & $1,22 / 21,20$ & $1,23 / 20,00$ & $1,16 / 19,20$ & $1,12 / 19,20$ & $1,20 / 20,04$ \\
\hline 14 & 01.03 .14 & $1,29 / 20,10$ & $1,20 / 21,00$ & $1,23 / 19,90$ & $1,15 / 19,20$ & $1,11 / 19,10$ & $1,20 / 19,86$ \\
\hline 15 & 02.03 .14 & $1,27 / 19,10$ & $1,19 / 19,30$ & $1,22 / 17,70$ & $1,14 / 17,10$ & $1,11 / 17,20$ & $1,18 / 18,08$ \\
\hline 16 & 03.03 .14 & $1,26 / 18,30$ & $1,18 / 18,90$ & $1,21 / 17,10$ & $1,13 / 16,90$ & $1,09 / 17,00$ & $1,17 / 17,64$ \\
\hline 17 & 04.03 .14 & $1,24 / 17,00$ & $1,18 / 16,40$ & $1,20 / 16,20$ & $1,12 / 16,50$ & $1,08 / 16,40$ & $1,16 / 16,50$ \\
\hline 18 & 05.03 .14 & $1,24 / 16,70$ & $1,18 / 16,30$ & $1,18 / 16,20$ & $1,10 / 16,20$ & $1,08 / 16,50$ & $1,16 / 16,38$ \\
\hline 19 & 06.03 .14 & $1,24 / 16,20$ & $1,17 / 16,00$ & $1,18 / 16,10$ & $1,11 / 15,80$ & $1,08 / 16,50$ & $1,16 / 16,12$ \\
\hline 20 & 07.03 .14 & $1,24 / 16,20$ & $1,17 / 15,90$ & $1,18 / 16,10$ & $1,11 / 15,80$ & $1,08 / 16,50$ & $1,16 / 16,10$ \\
\hline 21 & 08.03 .14 & $1,24 / 16,20$ & $1,16 / 15,90$ & $1,18 / 16,00$ & $1,11 / 15,80$ & $1,07 / 16,50$ & $1,15 / 16,08$ \\
\hline 22 & 09.03 .14 & $1,24 / 16,20$ & $1,16 / 15,90$ & $1,18 / 16,00$ & $1,11 / 15,80$ & $1,06 / 16,50$ & $1,15 / 16,08$ \\
\hline 23 & 10.03 .14 & $1,20 / 16,20$ & $1,16 / 16,00$ & $1,18 / 16,00$ & $1,09 / 15,80$ & $1,06 / 16,00$ & $1,14 / 16,00$ \\
\hline 24 & 11.03 .14 & $1,20 / 16,20$ & $1,16 / 16,00$ & $1,18 / 16,00$ & $1,09 / 15,80$ & $1,06 / 15,90$ & $1,14 / 15,98$ \\
\hline 25 & 12.03 .14 & $1,20 / 16,20$ & $1,16 / 16,00$ & $1,18 / 16,00$ & $1,09 / 15,80$ & $1,06 / 15,90$ & $1,14 / 15,98$ \\
\hline 26 & 13.03 .14 & $1,20 / 16,20$ & $1,16 / 16,00$ & $1,18 / 16,00$ & $1,09 / 15,80$ & $1,06 / 15,90$ & $1,14 / 15,98$ \\
\hline
\end{tabular}

Источник: Собственная разработка.

Source: Own elaboration.

На двадцать пятый день исследований массы образцов хвои, и ёмкости конденсатора с образцами не изменились по сравнению с предыдущим днем. Измерения, проведенные на двадцать шестой день, подтвердили это, и поэтому эксперимент был прекращен. Во время второго этапа исследований определяли влажность хвои. С этой целью образцы разместили в сушильной камере и выдерживали при температуре $100 \pm 5^{\circ} \mathrm{C}$ в течение 3 часов до абсолютно сухого состояния. Перед началом сушки произвели контрольные измерения массы и ёмкости. Результат был аналогичный полученному на 26-й день опытов. После завершения сушки определили массу образцов и ёмкость конденсатора с хвоей между пластинами (табл. 2).

Таблица 2. Масса образцов хвои и ёмкости конденсатора с хвоей в абсолютно сухом состоянии Table 2. Mass of needles samples and capacitance of the capacitor with needles after drying until completely dry state

\begin{tabular}{|c|c|c|c|c|c|}
\hline \multicolumn{7}{|c|}{ Масса образцов, г / Ёмкость, пФ / Mass of samples, $\mathbf{g}$ / Capacitance, $\mathbf{p F}$} \\
\hline \multicolumn{7}{|c|}{ Образцы / Samples } \\
\hline $\mathbf{1}$ & $\mathbf{2}$ & $\mathbf{3}$ & $\mathbf{4}$ & $\mathbf{5}$ & $\begin{array}{c}\text { Среднеe значение / } \\
\text { Average value }\end{array}$ \\
\hline $1,11 / 14,20$ & $1,06 / 14,00$ & $1,09 / 14,00$ & $1,01 / 14,70$ & $0,90 / 14,90$ & $1,03 / 14,36$ \\
\hline
\end{tabular}

Источник: Собственная разработка.

Source: Own elaboration.

По значениям массы образцов в табл. 1 и 2 вычислили среднее значение влажности хвои. Зависимость средней влажности хвои от времени сушки изображена на рис. 1.

Средние значения ёмкости конденсатора с хвоей между пластинами, полученные в ходе эксперимента, изображены на рис. 2.
Объединив результаты, получили зависимости для оценки влажности хвои по ёмкости конденсатора с хвоей между пластинами (рис. 3). 


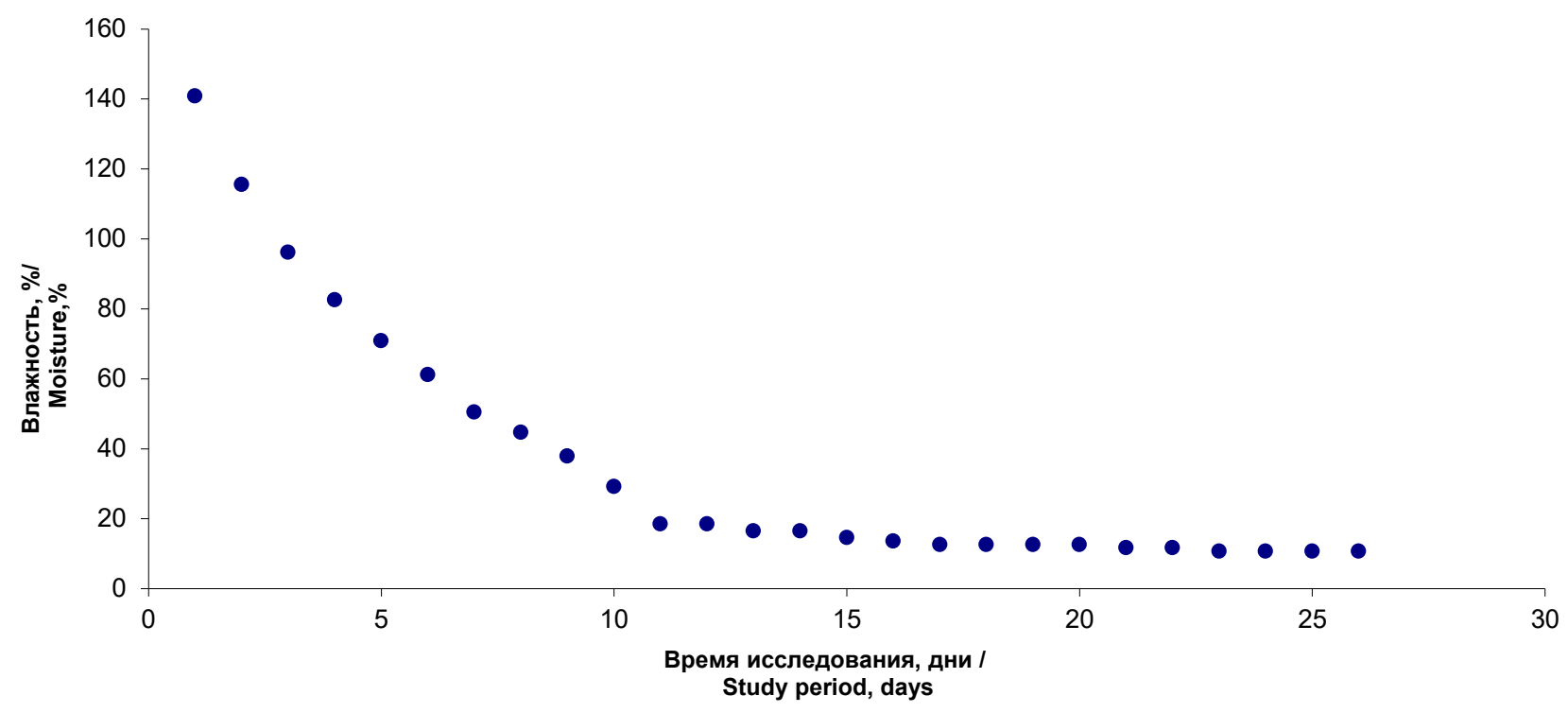

Рис.1. Зависимость влажности хвои сосны обыкновенной от времени сушки

Fig. 1. The dependence of pine needles moisture on drying time

Источник: Собственная разработка.

Source: Own elaboration.

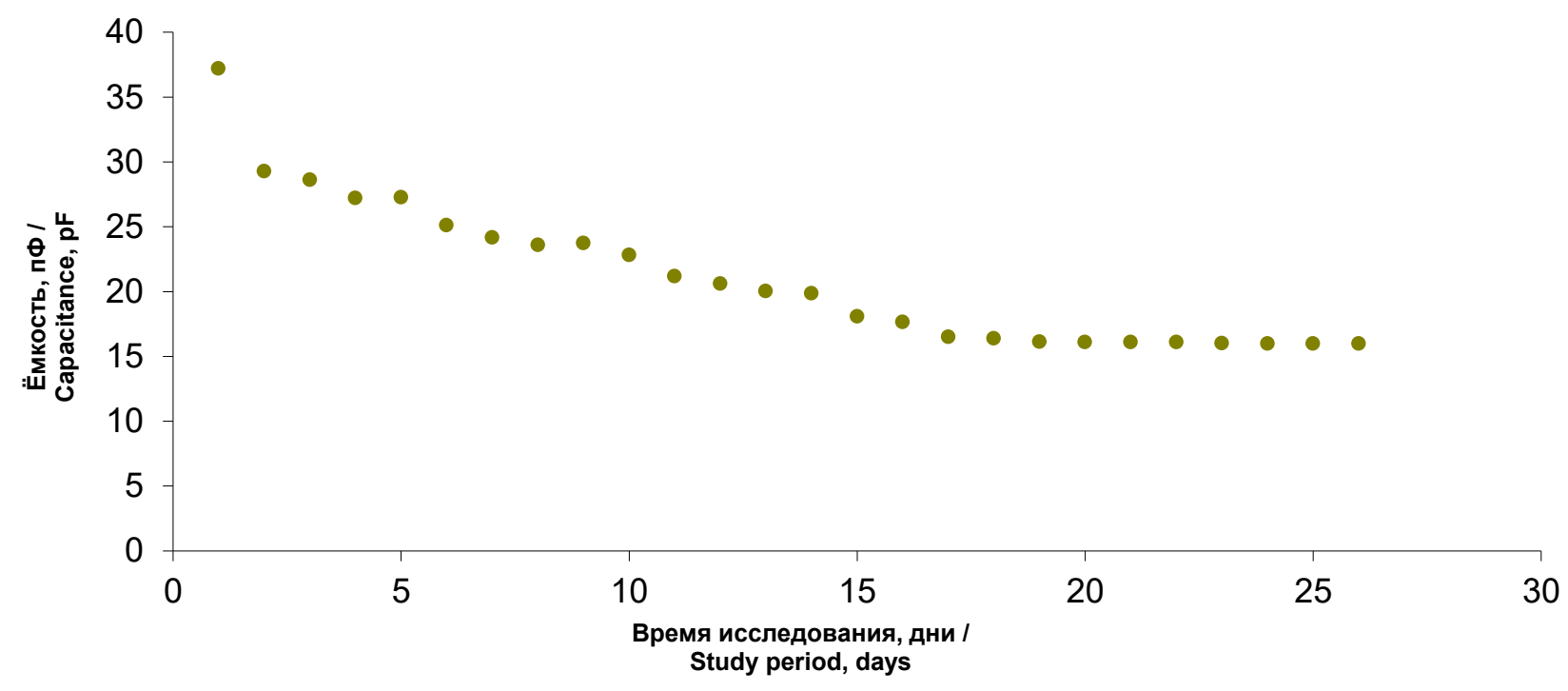

Рис. 2. Зависимость ёмкости конденсатора с хвоей от времени сушки

Fig. 2. The dependence of capacitance of the capacitor with needles samples on drying time

Источник: Собственная разработка.

Source: Own elaboration. 


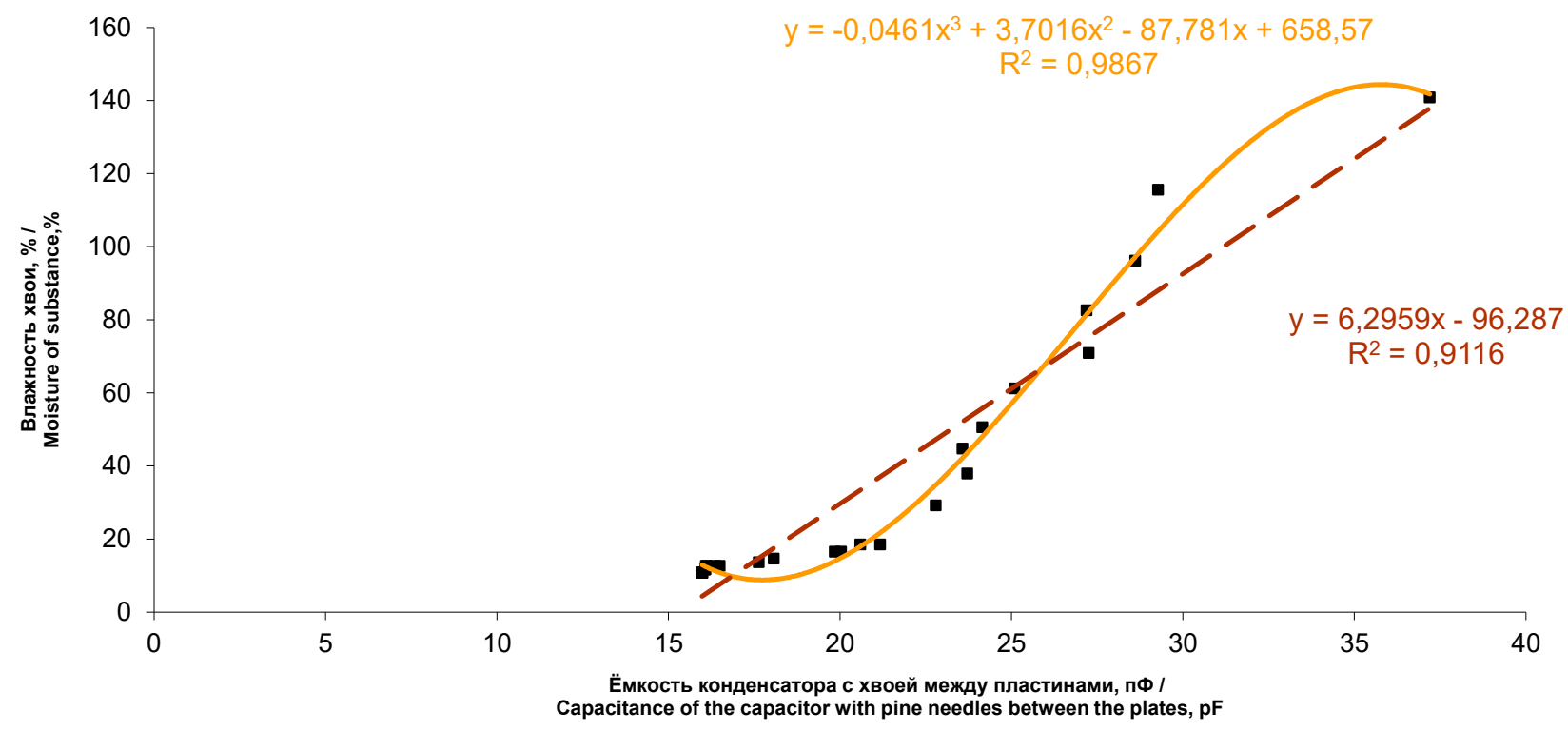

Рис. 3. Зависимости для оценки влажности сосны обыкновенной по ёмкости конденсатора с хвоей между пластинами Fig. 3. Dependence for estimation of pine needles moisture on the basis of the capacitor's with needles between the plates capacitance

Источник: Собственная разработка. Source: Own elaboration.

\section{5. Дискуссия над методами и результатами}

В первый день исследований при измерении ёмкости этот показатель был нестабильным и требовал большего времени определения, чем в последующие дни. Наблюдения показали, что ёмкость конденсатора для каждого образца хвои в процессе измерения постоянно уменьшалась и совершала определенные колебания до достижения постоянного значения. Этот факт объясняем тем, что, возможно, в свежесорванной хвое происходят определенные биофизические изменения под влиянием электрического поля. Результаты исследований показали, что масса хвои и ёмкость конденсатора с хвоей со временем уменьшаются одновременно. При этом полученные зависимости влажности хвои и ёмкости конденсатора с хвоей от времени являются нелинейными, что свидетельствует о непостоянных скоростях изменения этих показателей. Зависимость влажности хвои сосны обыкновенной от ёмкости конденсатора с хвоей между пластинами наиболее точно описывает полиномиальная регрессионная модель $W=-0,0461 C^{3}+3,7016 C^{2}-87,781 C+658,57$ с коэффициентом детерминации $R^{2}=0,9867$,где $C$ - ёмкость конденсатора с внесенной хвоей между пластинами конденсатора, пФ. Неплохое приближение дает и линейная модель $W=-6,295996,287$ с $R^{2}=0,9116$.

Расчет непосредственно диэлектрической проницаемости хвои сосны обыкновенной по ёмкости конденсатора с образцами затруднен, поскольку между его пластинами содержится не только хвоя, но и воздух. Но поскольку ёмкость конденсатора с малым расстоянием между пластинами прямо пропорциональна диэлектрической проницаемости среды, то отсюда следует, что по изменению емкости можно оценивать диэлектрическую проницаемость хвои. Поэтому с целью практического применения в экспресс-диагностике пожарной опасности хвои сосны обыкновенной по ее влажности считаем целесообразным учитывать значения ёмкости конденсатора постоянных геометрических размеров, между пластинами которого размещено образцы хвои.

\section{6. Выводы}

1. В результате экспериментальных исследований влажности хвои сосны обыкновенной и ее диэлектрической проницаемости, отображенной в ёмкости конденсатора с хвоей между пластинами, установлено, что оба показателя одновременно уменьшаются в процессе сушки.

2. Полученные эмпирические модели позволяют определять влажность хвои сосны обыкновенной как одну из наиболее важных характеристик пожарной безопасности по ёмкости конденсатора с хвоей между пластинами. 


\section{Литература}

[1] Melekhov I. S., Lesnyye pozhary i bor'ba s nimi, Severnoye krayevoye izd-vo, Arkhangel'sk, 1935.

[2] Gosudarstvennoye agentstvo lesnykh resursov Ukrainy., Lesa Ukrainy, Karta lesov Ukrainy [electr. doc.], http:// dklg.kmu.gov.ua/forest/control/uk/publish/article?art_ id=33506\&cat_id=32867, [accessed: 03.06.2014]

[3] Svyrydenko V.E., Babich O.G., Shvydenko A.Y., Lesnaya pirologiya, Agropromvydav Ukrainy, Kiyev, 1999.

[4] Ivanov M.A., Khimiya drevesiny i tsellyulozy, Lesnaya promyshlennost', Moskva, 1982.

[5] Biley P.V., Sushka i zashchita drevesiny, izdatel'stvo L'vovskogo natsional'nogo lesotekhnicheskogo universiteta Ukrainy, L'vov, 2008.

[6] Afzal A., Estimation of leaf moisture content by measuring the capacitance, "J. Agr. Sci. Tech." Vol. 12, 2010, pp. 339-346.

[7] Stevens W.R., Stickel on the measurement and interpretation offorest-fire weather in the Western Adirondacks, "Monthly Weather Review", January, 1932, p. 25.

Кузык Андрей Данилович - ученый секретарь Львовского государственного университета безопасности жизнедеятельности. Доктор сель.-хоз. наук, кандидат физ.-мат. наук, профессор. Область научных интересов: теоретические и экспериментальные исследования процессов горения, пожарной опасности лесов и пожароопасных свойств горючих материалов растительного происхождения.

Товарянський Владимир Игоревич - адъюнкт Львовского государственного университета безопасности жизнедеятельности. Область научных интересов: теоретические и экспериментальные исследования пожарной опасности молодых хвойных насаждений. 